\title{
How do the Vietnamese lose face? Understanding the concept of face through self-reported, face loss incidents
}

\author{
Pham Thi Hong Nhung \\ Hue University of Foreign Languages, Hue city, Vietnam \\ Email address: \\ nhungpham76@yahoo.com
}

To cite this article:

Pham Thi Hong Nhung. How Do the Vietnamese Lose Face? Understanding the Concept of Face through Self-Reported, Face Loss Incidents. International Journal of Language and Linguistics. Vol. 2, No. 3, 2014, pp. 223-231. doi: 10.11648/j.ij11.20140203.21

\begin{abstract}
In Western universal theory, face has been considered as an individual possession, a fundamental motivation for politeness and driven by the concern for autonomy as well as the desire to be free from imposition. However, research on face and politeness in a number of East Asian countries has provided evidence that such a way of conceptualizing face may not be valid to these cultures and languages. Given the scarcity of research on the concept of face in Vietnamese, this paper explores face in Vietnamese by means of self-reported incidents where a sense of face loss (mất mặt or mất thể diện) was felt. Scenarios reconstructed from collected authentic incidents were used to examine whether different participants responded in the same way to situations perceived as potentially causing loss of face. The findings have confirmed that face in Vietnamese is both an individual and collective possession and a subjective value, conditionally dependent on social evaluation.
\end{abstract}

Keywords: Face, Vietnamese, Politeness, Face Loss

\section{On the Definition of Face}

The term "face" in English, as derived from the literal translation of the two Chinese characters mien/mianzi (面子), and lien/lian (脸) (Mao, 1994) was not adopted into English until the early $19^{\text {th }}$ century when John Morrison first used the phrase "to lose face" in his Chinese commercial guide book in 1834 (André, 2013). However, the earliest references to this Confucian-based concept (Cheng, 1986) are found in ancient documents as early as the $4^{\text {th }}$ century B.C. (for mien/mian), and the 13th century (for lien/lian) ( $\mathrm{Hu}, 1944)$.

Face did not receive much attention until the $20^{\text {th }}$ century where it gained importance in the field of pragmatics (Kádár and Pan, 2012). In 1967, Goffman further developed the Chinese concept of face by associating it with "a pattern of verbal and nonverbal acts by which [one] expresses his view of the situation and through this his evaluation of the participants" (1967 p.5). He then presented a number of collocations of face, including "have face", "be in face", "be out of face", "be in wrong face" and "maintain face" and claimed that in Anglo-American culture, "to lose face" means to be in wrong face or out of face while saving face refers to "the process by which the person sustains an impression for others that he has not lost face" (Goffman, 1967 p.13). Drawing on Goffman's (1967) way of conceptualizing face,
Brown and Levinson $(1978,1987)$ proposed a model of politeness centred on the concept of face. In their model, "face is something that is emotionally invested, and that can be lost, maintained, or enhanced, and must be constantly attended to in interaction" (1978 p.61) and the content of face may differ across cultures, but people's knowledge of their public self-image (i.e., face and the tendency to orientation to face in interaction) is universal. Their concept of face is realized in two sophisticated aspects: positive face and negative face. Positive face refers to one's want or desire to be admired and approved of by other people; and negative face refers to one's desire or want to be free from any imposition.

\section{Face across Cultures and Politeness}

\subsection{Face-Threatening Acts and Politeness}

Brown and Levinson confirm that any utterance can be face-threatening, i.e., it runs the risk of making other(s) or the speaker lose face, and so any speech act can be a face threatening act. Any utterance can negatively influence one's own and/or the other's face (i.e., one's own and/or the other's want of being approved, and of being fully free from imposition). For example, the utterance "Close the window 
now" violates one's want of being free from imposition, because this utterance is asking one to do something without one's want, threatening one's negative face, and hence is not polite. Asking someone to do something without directly threatening his/her face is when politeness comes into play. To be polite, one must use different strategies such as indirectness (e.g., by using questions like "Could you close the window please?"), giving hints (e.g., "It is so cold in here."), or combining the two (e.g., "It is cold in here, isn't it?"). Such strategies help interlocutors attend to each other's face. Brown and Levinson place strong emphasis on the correlation between imposition (negative face) and politeness. By reducing the possibilities in which imposition may occur, and by reducing the degree of imposition of speech acts when imposition does have to occur, people involved in linguistic interactions help save each other's face, and hence are polite. This view presents face, particularly the respect for each other's desire to be free from imposition, as the fundamental, and possibly the only, motivating force for politeness (Spencer-Oatey, 2000), and it makes Brown and Levinson's theory a theory of face and face-work, rather than a theory of politeness (Watts, 2003 p.97; Pham, 2007, 2011).

The theories of politeness and face, especially Brown and Levinson's, have established their place in the literature on politeness and have, to various extents, been supported in much research on linguistic politeness in English-speaking cultures. As the most developed theory of politeness, Brown and Levinson's face loss prevention view has been the most influential single framework in providing a paradigm for the investigation of linguistic politeness (Kasper, 1990; Watts, 2003; Watts, Ide, \& Ehlich, 1992). Its influence has been widely recognized: "it is impossible to talk about it [politeness] without referring to Brown \& Levinson's theory" (Orecchioni, 1997:11). Their model of politeness has been supported by various studies on different politeness speech acts, for instance, in complimenting (e.g., Herbert, 1989; Henderson, 1996; Nelson, Al-Batal, \& Echols, 1996), in requesting (e.g., Holtgraves \& Yang, 1992; Yeung, 1997), in apologizing (e.g., Berman \& Kasper, 1993; Suszczynska, 1999), in expressing disagreement (e.g., Holtgraves, 1997), and in many different domains such as health (e.g., Spiers, 1998; Hummert \& Mazloff, 2001), organizational interactions (e.g., Morand, 1996; Harris, 2003;), business interactions (e.g., Yeung, 1997; Yli-Jokipii, 1994), educational interactions (e.g., Rees-Miller, 2000), and language teaching (e.g., Wolfson, 1981; Weizman, 1989). Furthermore, although Brown and Levinsons's theory was originally designed to analyse oral discourse, it has also been applied to research on written discourse (e.g., Hagge \& Kostelnick, 1989; Graham \& David, 1996).

\subsection{Research on the Concept of Face and Politeness in East Asian Cultures}

Research on the concept of face and its connection with politeness in a number of Asian cultures, extensively Chinese and Japanese has provided empirical evidence for the invalidity of Brown and Levinson's $(1978,1987)$ face model, especially on their claims of the universality of face components (i.e., negative and positive face) and of its relation to politeness behaviour.

\subsubsection{The Chinese Concept of Face}

Gu (1990) critically compared western notions of face and politeness with their Chinese counterparts. He claims that Chinese politeness phenomena are governed by social norms rather than by individuals' wants. This view is supported by much other research (e.g., Chen, 1993; Smith \& Bond, 1994; Gao, 1998a, b; Takaku, Weiner, \& Ohbuchi, 2001). For instance, Chen (1993) found that the Chinese subjects had a significantly higher rate of compliment rejection than their American counterparts. In the light of Brown and Levinson's face-saving theory, rejecting compliments is face-threatening in the sense that any rejection may threaten the compliment giver's positive face (i.e., the desire to be approved of). From another perspective, refusing a compliment may make the givers of the compliment feel that their praise is not welcome. As a result, in order to prevent others and oneself losing face, the receiver should accept the compliment. By accepting the compliment the receiver of the compliment is thereby polite. Nevertheless, the Chinese data in Chen's research show the opposite: the denial of compliments is polite. Other research in the same field has also suggested that Chinese face may not be the same as the concept of face in Western culture.

Following Fillmore and Atkins (1992) Ervin-Tripp, Nakamura \& Jiansheng (1995) showed the benefits of examining a concept on the basis of collocations (i.e., common expressions) and took the first steps towards an examination of face based on its collocational possibilities. Haugh \& Hinze (2003) analyse the Chinese concept of face on the basis of common expressions where the words mianzi and lian appear in Chinese. They suggest that the management of face as well as judgments and attitudes towards face in Chinese can be explained by means of metalanguage (e.g., by examining its common expressions). In a recent research volume on Chinese concepts of face and politeness, Kádár and Pan (2012) seem to suggest that face and politeness, at least in Chinese, are not necessarily “inherently related" (p. 2).

\subsubsection{The Japanese Concept of Face}

Matsumoto's (1988, 1989) work on Japanese face and politeness also challenges the Anglo constructions regarding the components of face and their relation to politeness. Using Japanese examples Matsumoto highlighted the importance of "social identity" in the Japanese concept of face. He illustrates the discrepancy between the Japanese notion of face and that of Brown and Levinson, and argues that the latter makes erroneous predictions for Japanese politeness. Japanese face does not include the negative face aspects, i.e., where the individual wants to be free from impositions as described in Brown and Levinson's model and by their 
advocates. In order to be polite, a Japanese person must understand his/her position in relation to that of others, and must verbally acknowledge his/her dependence on others. "Acknowledgement and maintenance of the relative position of others, rather than preservation of an individual's proper territory, governs all social interaction" (Matsumoto, 1988, p. 405). Further investigating politeness in Japanese, Ide (1989) maintains that discernment - "the choice of linguistic form or expression in which the distinction between the ranks or the roles of the speaker, the referent and the addressee are systematically encoded" (p. 230) - rather than the individual's wants concerning face govern Japanese linguistic politeness strategies. These views, of Japanese face not containing the negative aspects of face of Anglo theories are supported by other work (e.g., Pizziconi, 2003)

Research on Chinese face and Japanese face has confirmed Mao's (1994) comment that face in these two cultures gravitates towards hierarchical interdependence and social recognition, and both are oriented toward an ideal social identity rather than to an ideal individual autonomy.

\subsubsection{Research on the Vietnamese Concept of Face}

As Ervin-Tripp, Nakamura \& Jiansheng (1995) observe, Asian languages have a wide range of expressions involving the term face (i.e., collocational abilities for the word "face"). Vietnamese is no exception. In Vietnamese the two equivalent concepts are mặt (from mian/mien), and thể diện (from lien/lian). Unlike mặt, thể diện, as the modern variation of the figurative concept of face, does not literally have a physical referent, but rather refers to the general social image a person claims for him- or herself ( Vu, 2002; Pham, 2007; 2011).

Pham $(2007,2011)$ explores the Vietnamese concept of face respectively through the collocations of "mặt" and "thể diện" in Vietnamese daily written texts (i.e., the participants were asked to make sentences containing the term mặt or thể diện) and literary texts. Her data show that the Vietnamese concept of face as expressed in mặt and thể diện has various referents. Literally, mạt is used to refer to the upper front part of the body, as manifested in common phrases such as: tố $i$ tăm mắt mũi or xây xẩm mặt mày - a sense of hangover (literally: dizzy face and nose), or mặt hoa da phấn - a beautiful face (literally: flower face, powdered skin).

Mặt can also be used to replace the subject of an action, or the human being who performs the act which is being described: vắng/mất mặt - being absent (literally: absent face), vác mặt/mò mặt - showing/turning up (literally: bringing face), cách mặt - being out of sight (literally: separating face), tù mặt - giving up associating with (literally: abandoning face), and tránh mặt - avoiding meeting someone (literally: avoiding face).

Pham's $(2007,2011)$ suggests that the Vietnamese concept of face is made up of social roles and role-driven characteristics, positive qualities and achievements., These are closely associated with Spencer-Oatey's (2000) concept of "identity face" and "social role face" and with Brown and
Levinson's "positive face" since they promote the individual's want to be approved of, and appreciated by, other people. The Vietnamese data in her studies also show that face in Vietnamese is of both individual and collective quality, and includes image and possession.

Nguyen's (2014) recent study involves interviewing Vietnamese teachers about their perceptions of thể diện. Her data suggest that thể diẹn represents a specific Vietnamese concept of face, commonly perceived as being a person's image in social evaluations and attached to a sense of shame rather than guilt. However, it is not clear in her paper what thể diện, and hence face, is comprised of.

This review has shown that there are controversies over the definition of face across cultures, as well as in whether preventing face loss is a motivation for politeness.

Instead of making the assumption that face is inherent by asking the participants to explain what they think face means (e.g., Nguyen, 2014), the current study is an attempt to explore the Vietnamese concept of face through incidents where the participants reported a sense of mất mặt or mất thể diẹn (face loss). Further, by asking the participants to explain why they felt a loss of face in the reported specific authentic incidents, it is hoped that the components of face in Vietnamese culture becomes clearer.

\section{Research Design}

\subsection{Research Questions}

The present study aims to answer two main research questions.

Research question 1: What is face as indicated in the Vietnamese self-reported, face loss incidents and what are the perceptions of the consequences of face loss?

Research question 2: Is face an objective value or phenomenon?

\subsection{Participants}

73 participants took part in the data collection process of this current study. These participants were selected at random and in social relationships with the researcher. Their age range is from 18 to 73 . The participants work in different occupational categories, varying from high school students to pensioners. They were divided into two groups. Group 1 contains 53 participants who were asked to report face loss incidents. Group 2 is made of 20 participants who were interviewed on how they would feel in one of a set of ten scenarios re-constructed from incidents reported by group 1 participants.

\subsection{Research Method}

\subsubsection{Self-Reported Face Loss Incidents}

The participants were informed of the data collection procedure in which all the information they provided would be kept confidential and used only for the purposes of the 
study. The participants were asked to describe in Vietnamese written form at least two (2) incidents which they thought caused them mất mặt or mất thể diện (face loss). The self-reported written format was delivered to the participants both in hardcopy and electronic version. The self-reported format suggests that participants: 1) provide their personal information including age range and occupation; 2) describe the context of the incident(s) including information about the setting and the time of incident(s) as well as the people involved in the incident(s); 3 ) describe the course of direction of the incident(s), i.e., what happened; and 4) explain why the participants felt a loss of face in the reported incident(s).

A total number of 129 authentic incidents were collected and used for data analysis.

\subsubsection{Interviewing on Re-Constructed Scenarios}

Of the 129 reported incidents, ten incidents were selected at random and modified. Retained information included the context reported to cause a face loss to the participant, including the setting, the people involved and the course of action. All information about how the group 1 participants felt in the original situations was removed. Personal information about the group 1 participants and their personal explanation of face loss were used selectively to add to the original descriptions in order to provide more socio-pragmatic information to the group 2 participants, who were asked to put themselves in those situations and state how they would feel. Re-wording was provided to facilitate the group 2 participants' projection. To illustrate this process, an original self-reported, face loss incident and its modified version are provided as follows:

Original version:

"1. Personal information:

Age range: 18-25; Occupation: high school teacher

2. Setting and time and people involved:

At home, in the evening, my parents, my student and me

3. Happenings:

I was sitting in the living room watching TV with my parents. I was wearing a rather worn t-shirt and my favourite short jeans when some students of mine suddenly appeared at the door. It was mất mạt (face loss) as when I saw them, they were already on the doorstep and saw me in very casual, shabby clothes."

4. Explanation of face loss:

I want to project myself as a proper, exemplary teacher and I am careful about what I wear in front of my students and colleagues. I always dressed properly at school. I want to be respected. When my students turned up suddenly at my house without any notice in advance and saw me in very casual clothes, it was very embarrassing. I felt mất mặt (a face loss)."

Modified version:

"You are in your twenties and a high school female teacher. You want to project yourself as a proper, exemplary teacher and so you are careful about what you wear in front of your students and colleagues. You always dress properly at school.

One evening you were sitting in the living room, watching
TV with your parents. You were wearing a rather worn t-shirt and your short jeans when some students of yours suddenly appeared at the door. When you saw them, they were already on the doorstep and saw you in very casual, shabby clothes. How would you feel?

The set of ten scenarios selected and re-constructed from group 1 participants' self reported incidents were then used in interviews with the group 2 participants. To start with, the participants were asked to read through the incidents and for each incident, they were requested to say how they would feel in each situation. In the initial stage of the interview, no direct reference to mặt or thể diện was made during the interview process unless it was brought up by the participants In cases where the participants had finished saying how they would feel in a particular scenario and did not mention mất mặt or thể diện, they would be further asked whether they would feel a loss of face in that situation and why or why not.

\section{Findings}

Among 129 face loss incidents reported, 112 incidents involved the participants mentioning mất mặt rather than mất thể diện. This suggests that when they have choice (i.e., to report incidents which caused them mất mặt or mất thể diện), the Vietnamese prefer to link face with $m a ̣$ t rather than with thê diện. This is in line with the observation that, in Vietnamese, collocations using mặt outnumber those using thể diện and although these two terms can be used interchangeably in common expressions of losing face (mất mặt / mất thể diện) (Pham, 2007, 2011), there are a great number of collocations in which thể diện cannot be used in place of mặt. To name a few, collocations such as đẹp mặt (enhancing face), xấu mặt (humiliating face), lên mặt (showing off one's face [i.e., role or achievement]) are very common but it is awkward to say đep thể diện, xấu thể diện or lên thể diện. In contrast, mặt cannot replace thể diện only in two cases - references to collective face, for example: thể diện quốc gia (literally: face of the country) and the expression of maintaining face: giũ thể diẹn (literally: keeping face). A similar tendency is found in the interview data. Of the total of 200 responses by 20 participants to the ten moderated scenarios, 146 responses contain references to face loss and all of these references directly involve mất mặt, not mất thể diện. This is partially explained by the fact that the term thể diện tends to refer to group face while the participants in the current study were asked to describe incidents where they themselves felt face loss (i.e., more associated with face at an individual or personal level). However, this also shows that in the Vietnamese concept of face, mặt functions much more vigorously and is referred to more often than thể diện.

\subsection{Failure to Protect Social Roles and Identity Qualities as Face Loss}

Self-reported, face loss incident corpus shows that face is a very sensitive phenomenon as Vietnamese may feel a face 
loss from minor occurrences to serious happenings. Whenever there is a sense of having their projected positive qualities or social role or role-driven rights being threatened, face is perceived as being lost. The following examples illustrate this.

(1). Personal information:

Age range: 65-70; Occupation: pensioner

Setting and time and people involved:

In the tour, June 2013, neighbours

Happenings:

I joined a group of pensioners from my neighbourhood in a tour to Cambodia. It was 7-day tour. I don't like mobile phones because I think they are a nuisance. I have one mobile phone but I never use it as I'm rarely away from home for too long. Before the tour, my husband and my children asked me to take one [mobile phone] to ease communication between us but I decided not to take one. However, when I got on the coach for the tour, I realized that almost everybody else used a mobile phone. And as my family was worried about me, they called me using other neighbours' numbers. I felt mất mặt [face loss].

Explanation of face loss:

They [my neighbours] may think that I am too mean to have a mobile phone or can't afford it. This is not true. It's embarrassing if they think so.

The incident reported in (1) indicates the participant's concern about her neighbours possibly thinking that she was mean and not able to afford a mobile phone for herself. Her feeling of having lost face in this incident shows that the possession of a common thing, such as mobile phone, is part of the participant's face, i.e., the ability to have things that many other have and the commonsense in spending habit.

(2). Personal information:

Age range: 31-35; Occupation: bank clerk

Setting and time and people involved:

In the evening, in a restaurant, old friends and me Happenings:

My old friends and I were having a drink in a restaurant. They are my friends from high school time. We used to be very close but after we graduated from university, they both left our hometown and settled down in Da Nang [a city about $100 \mathrm{~km}$ away from where the participant is]. So we don't meet very often. While we were talking about the time that had passed and the memories since school time, my wife called to urge me home. I had told her before that I would get home later than usual that day but she kept calling several times. Although my friends did not say anything about that, it was really mất mặt (face loss).

Explanation of face loss:

I don't want my friends to think that my wife is bossy to me. Even worse they may think that I'm afraid of her. I am a man and of course nobody wants to be thought of as a man strictly controlled by his wife but they [my friends] are both single, so they may not really understand it. They may laugh at me or not respect me.

In (2), the participant's interpretation shows that the fact that his wife called him several times to ask him to go home made him lose face to his old friends. His wife's act of calling him is perceived to threaten his image as a man not strictly controlled by his wife. In other words, his role as a husband is not respected.

As seen in the examples above, face is lost in the presence of a second and/or third party or when the event is known to a second or third party as further revealed in the following example:

(3). Personal information:

Age range: 26-30; Occupation: post office division head

Setting and time and people involved:

In meeting at work, in the morning, boss and colleagues

Happenings:

I was assigned to implement a small reform project at work. It was to improve the process of delivering Express Postage of our post office. I had discussed possible measures with staff members in my division and we were taking actions to reduce the time it took for home delivery, especially on the weekends. However, on the weekly meeting about 3 weeks after the official assignment, my intermediate boss said the delivery section had not made any progress and he hadn't heard anything about how everything was going. I felt mất mặt (face loss) and explained to him.

Explanation of face loss:

He said that in a meeting, in the presence of all of my staff. It was not fair and also not true as we all took action to improve the delivery system. I had also kind of mentioned that to him once before, so it's not so right to say that he hadn't heard anything about it. I felt a face loss because what he said may make my staff think wrongly about me. They may think I am not responsible and that would influence trust between us.

The participant in (3) felt his face was lost because what the boss said about him in front of his supporting staff may harm his image as a responsible or active manager.

In all 129 incidents, there is no evidence that the concern for face is associated with the desire to be free from imposition. There is one case where face loss it related to politeness but politeness is not the concern for face; rather it is perceived as a quality projected by the participant:

(4). Personal information:

Age range: 26-30; Occupation: policeman

Setting and time and people involved:

In the afternoon, in a friend's house

Happenings:

My girl friend lives with her parents and her little brother. I dropped by her house after my guard and had a fun talk with them [her brother and parents] while waiting for her to get home from work. While we were talking, she called and asked me to get her home. I didn't want to keep her waiting for too long, so I left in a hurry without telling them [her parents and brother] that I was going to pick her up]. Later I felt a little mất mặt (face loss).

Explanation of face loss: 
I don't want them to think that I'm not polite and [that] I do not know how to behave properly (originally, vô ý vô tu').

The example in [4] indicates that being polite is part of the image or the quality the participant wants to project of himself, i.e., face. It is not necessarily true that because he cares about his face, he is polite. Being evaluated as vô $y^{\prime} v \hat{o}$ tú in Vietnamese is being perceived as a moral deficiency. The participant's interpretation that he does not want to be considered as a person not knowing how to behave properly shows the care for face is associated with shame, not necessarily with politeness.

\subsection{Face as Both Individual and Collective Possession}

As shown in all examples above, face in Vietnamese is an individual possession and also a group quality. This can be seen in incidents where the participants reported either they felt the group with whom they identify lost face as a result of their behaviour or they felt a face loss on their own part as a result of the act of somebody else they associated with. This is illustrated in example (5) and (6) below.

(5). Personal information:

Age range: 18-25; Occupation: student

Setting and time and people involved:

On weekend, parents

Happenings:

Several weeks ago, I got a fine because I went through a red traffic light. I felt very embarrassed although I did not do it on purpose. I paid the fine and got my license punched. Several days later when my mother attended a regular meeting in my neighbourhood, a man from the quarter security force cited my name as an example of not respecting the traffic rule. I made my parents mất mặt [lose face].

Explanation of face loss:

When I paid the fine, I thought that was it. I had learned the lesson and paid the price for my carelessness. But it was not just me. What I did influenced my parents' reputation too. I brought shame on them.

It is obvious that the participant in (5) took face as a shared value. What he had done caused a face loss not just to him but also to his family.

In (6), the participant reported this shared aspect of face when he felt a face loss as a result of the group he gained membership with losing face.

(6). Personal information:

Age range: 26-30; Occupation: policeman

Setting and time and people involved:

In girlfriend's house, in the evening, girlfriend's parents and me

Happenings:

I was talking to my girlfriend in the front yard while her parents were watching a film on TV in the living room. They were discussing something that I couldn't hear clearly because of the noise from the TV. Then I heard her mother say: "He will get the money finally, you will see. Traffic policemen are all the same." I know it was not about me because I get on well with them and I am not a traffic policeman but I still felt annoyed and mất mặt (loss of face).

Explanation of face loss:

I think that they were talking about somebody else and they didn't mean me. But I felt mất mặt because I am also a policeman, in the police force. I feel a face loss when my fellows are not respected.

This confirms Pham's $(2007,2011)$ suggestions that, in Vietnamese, face is both an individual and a collective possession.

\subsection{Social Disapproval as Consequence of Face Loss}

As seen in all of the incidents reported, face loss can be caused by minor events or serious, consequential acts. The consequences of face loss, as commonly perceived by the participant, are in most cases associated with social disapproval of one's image (i.e., quality and roles) or the image of the group one has connections with. As illustrated, face loss can lead to a sense of embarrassment or social mockery. In some other cases, where a serious face loss is felt, it can also be perceived to lead to social condemnation as seen the example below.

(7). Personal information:

Age range: 56-60; Occupation: housewife

Setting and time and people involved:

In the open air market, street vendors, passengers

Happenings:

I went to the market for food when I heard a woman in a meat shop called my name. When I got close, she said I owed her money from last time I bought meat from her shop. I tried to explain that she must have mistaken me with somebody else. I never leave things unpaid but she insisted on me paying back the sum. It was really a mất mặt [face loss]. Finally I gave her the sum because it was not much and that was the best solution then. Several days later when her real customer returned the money, she apologized to me and gave it back to me. But I really felt humiliated.

Explanation of face loss:

I always pay in full when I go shopping. When she kept saying loudly that I refused to pay her money, it was very shameful, especially [when it happened] in front of many people. They may condemn me, thinking incorrectly that I am a fraud, getting her money.

It is observed that the common concern for the consequences of face loss is not associated with the others thinking of one as being impolite, but rather with being judged negatively or even not socially accepted.

\subsection{Face as Subjective Value}

Our analysis of group 2 participants' responses to ten incidents originally described as causing face loss by group 1 participants shows that among 200 responses, there are 146 cases in which group 2 participants actively thought a face loss occurred. For the other 54 cases, there are 22 cases where the participants did not mention face loss in their 
initial response but agreed that face loss might happen when they were directly asked whether they would feel so. However, for the remaining 32 cases, the partipants did not think that there was necessarily a face loss. The same incident could be perceived by some participants as causing face loss but may not perceived as such by others.

A close examination of these 32 cases where there is no consensus among the participants about whether face loss occurs or not reveals that these 32 cases link with 6 scenarios where in the original, self-reported incidents face loss was either minor or associated with group face or value. This all suggests that face in Vietnamese is a subjective value.

\section{Conclusion}

Starting with Goffman's 1967 concept, face has been developed by Brown and Levinson $(1978,1987)$ in their face-centred model of politeness face. Face in this model is expressed in the individual's want to be approved of, and the individual's want to be free from imposition. In other words, the desire to be loved, supported, and admired, and the desire to have full freedom in doing what one wants, have become key explanations in Western politeness behaviour.

Our analysis of Vietnamese self-reported, face loss incidents shows that face in Vietnamese as defined by mất mặt and mất thể diện is not completely synonymous with that of Brown and Levinson. In particular, the quality and image of the group as a component of face is not represented in Brown \& Levinson's model. In addition, if individual qualities and social roles, and the unique characteristics of the community that a person belongs to, can be considered static constituents - necessary conditions for the establishment of face - then the existence of face is subjective and conditional on another necessary condition: public judgment, which is beyond the control of the individual.

As Nwoye (1992) puts it in his pun on face: "Face is usually found to wear different cultural faces" (p. 228). An analysis of the face loss incidents of Vietnamese participants in this study has shown that the aspect of negative face, which is central to Brown \& Levinson's model, is not found in the Vietnamese concept of face. It is not that the Vietnamese are not concerned for autonomy in action, or about others' desire of freedom in action. In contrast, research has shown that Vietnamese are conscious of autonomy in action, and that this consciousness is shown in their strong tendency to employ indirectness in delivering addressee-costly acts such as requests (e.g., Vu, 2002). However, as revealed from this analysis of face loss incidents, the desire for autonomy is not a constituent of Vietnamese face. That is, the desire to act consistently with the individual's positive quality, and with the quality of the group, and with one's role, and hence one's role-driven rights, takes precedence over the desire to have rights to act independently (Spencer-Oatey, 2000, 2002; Pham, 2011, 2014). The present study shows that the Vietnamese do not feel that their face is threatened or lost when their autonomy is not respected. This supports the view that concerns about autonomy do exist in
Asian Confucian cultures, but they are not considered as aspects of face concerns (Gu, 1998).

\section{Acknowledgements}

The author wishes to thank Mr. Nguyen Van Bac and Ms. Pham Thi Tuyet Nhung for their valuable assistance in the data collection process.

\section{References}

[1] André, J. St. "How the Chinese lose "face"," Journal of Pragmatics, 55, pp. 68-85, 2013.

[2] Bergman, M. L. and Kasper, G. "Perception and performance in native and nonnative apology," in Interlanguage pragmatics, G.Kasper and S. Blum-Kulka, Eds. New York: Oxford University Press, 1993, pp. 82-107.

[3] Brown, P. and Levinson, S. "Universals in language usage: Politeness phenomena" in Questions and Politeness, E. N. Goody, Ed. Cambridge: Cambridge University Press, 1978, pp. 57-324.

[4] Brown, P. and Levinson, S. Politeness: Some Universals in Language Usage. Cambridge: Cambridge University Press, 1987.

[5] Cheng, C. Y. "The concept of face and its Confucian roots," Journal of Chinese Philosophy, 13, pp. 329-348, 1986.

[6] Chen, R. "Responding to compliments. A contrastive study of politeness strategies between American English and Chinese speakers," Journal of Pragmatics, 20, pp. 49-75, 1993.

[7] Ervin-Trip, S. Nakamura, K. and Jiansheng, G. "Shifting face from Asian to Europe," in Essays in semantics and pragmatics, M. Shitabai and S. Thompson, Eds. Amsterdam: John Benjamins, 1995, pp. 43-71.

[8] Fillmore, C. and Atkins, B. "Towards a frame-based organization of the lexicon: The semantics of RISK and its neighbours," in Frames, fields, and contrasts: New essays in semantics and lexical organization, A. Lehrer and E. Kittay, Eds. Hillsdale: Lawrence Erlbaum, 1992, pp. 75-102.

[9] Gao, G. "Don't take my word for it. Understanding Chinese speaking practices," International Journal of Intercultural Relations, 22, pp. 163-186, 1998a.

[10] Gao, G. "An initial analysis of the effects of face and concern for "other" in Chinese interpersonal communication," International Journal of Intercultural Relations, 22, pp. 467-482, 1998b.

[11] Goffman, E. Interaction Ritual: Essays in Face-To-Face Behavior. New York: Pantheon Books, 1967.

[12] Graham, M. and David, C. "Power and politeness: Administrative writing in an "organized anarchy"," Journal of Business and Technical Communication, 10, pp. 5-27, 1996.

[13] Gu, Y. "Politeness and Chinese face," Lecture given in the Department of Linguistics. University of Luton, summer 1998. 
[14] Hagge, J. and Kostelnick, C. "Linguistic politeness in professional prose: A discourse analysis of auditors' suggestion letters, with implications for business communication pedagogy," in Written Communication, 6, pp. $312-339,1989$.

[15] Harris, S. "Politeness and power: Making and responding to requests in institutional settings," in Text, 23, pp.27-52, 2003.

[16] Haugh, M. and Hinze, C. "A metalinguistic approach to deconstructing the concept of face and politeness in Chinese, English and Japanese," Journal of Pragmatics, 35, pp 1581-1611, 2003

[17] Henderson, A. "Compliments, compliment responses, and politeness in African-American community," in Sociolinguistic variation: Data, theory and analysis. Selected papers from NWAV at Stanford CA, J. Arnold, R. Blake, S. Schwenter and J. Solomon, Eds. California: Center for Language and Information Stanford, 1996, pp. 195-208.

[18] Herbert, R. K. "The ethnography of English compliments and compliment responses: A contrastive sketch," in Contrastive pragmatics, W. Oleksy, Ed. Amsterdam: Benjamins, 1989, pp. 3-35.

[19] Hotgraves, T. "Yes but...Positive politeness in conversation arguments," Journal of Language and Social Psychology, 16, pp. 222-239, 1997.

[20] Holtgraves, T. and Yang, J. "Interpersonal underpinnings of request strategies: General principles and differences due to culture and gender," Journal of Personality and Social Psychology, 62, pp. 246-256, 1992.

[21] $\mathrm{Hu}, \mathrm{H} . \mathrm{C}$. "The Chinese concept of face," American Anthropologist, 46, pp.45-64, 1944.

[22] Hummer, M. and Mazloff, D. C. "Older adults' responses to patronizing advice: Balancing politeness and identity in context," Journal of Language and Social Psychology, 20, pp. 168-196, 2001.

[23] Ide, S. "Formal forms and discernment: Two neglected aspects of universals of linguistic politeness," in Multilingua, 8, pp. 223-257, 1989.

[24] Kádár, D. Z. and Pan, Y. "Chinese "face" and im/politeness: an introduction," Journal of Politeness Research, 8, pp. 1-10, 2012.

[25] Kasper, G. "Linguistic politeness: Current research issues," Journal of Pragmatics, 14, pp.193-218, 1990.

[26] Mao, L. R. "Beyond politeness theory: Face revisited and reviewed," Journal of Pragmatics, 21, pp. 451-486, 1994.

[27] Matsumoto, Y. "Reexamination of the universality of face: Politeness phenomena in Japanese," Journal of Pragmatics, 12, pp. 404-426, 1988.

[28] Matsumoto, Y. "Politeness and conversational universals Observations from Japanese,” Multilingua, 8, pp. 207-221, 1989.

[29] Morand, D. A. "Dominance, deference, and egalitarianism in organizational interaction: A sociolinguistic analysis of power and politeness," Organization Science, 7, pp, 544-556, 1996.

[30] Nelson, L. G., Al-Batal, M, and Echols, E. "Arabic and
English compliments: A cross-cultural study," Applied Linguistics, 17, pp. 409-432, 1996.

[31] Nguyen, T. Q. T. "Thể diện: The Vietnamese concept of face Perceptions of teacher from Nha Trang". Unpublished PhD thesis. La Trobe University, Victoria, Australia, 2014.

[32] Nwoye, O. "Linguistic politeness and socio-cultural variations of the notion of face," Journal of Pragmatics, 18, pp. 309-328, 1992.

[33] Orechioni, K. C. "A multilevel approach in the study of talk in interaction,” Pragmatics, 7, pp. 1-20, 1997.

[34] Pham, T. H. N. "Vietnamese concept of face: evidence from its collocational abilities," E-journal of Foreign Language Teaching, 4, pp. 257-266, 2007.

[35] Pham, T. H. N. Communicating with Vietnamese in Intercultural Contexts: Insights into Vietnamese Values. Vietnam: Educational Publishing House, 2011.

[36] Pham, T. H. N. "Strategies employed by the Vietnamese to respond to compliments and the influences of compliment receivers' perception of the compliment on their responses," International Journal of Linguistics, 6, pp. 142-156, 2014.

[37] Pizziconi, B. "Re-examining politeness, face and the Japanese language," Journal of Pragmatics, 35, pp. 1471-1506, 2003.

[38] Rees-Miller, J. "Power, severity, and context in disagreement," Journal of Pragmatics, 32, pp. 1087-1111, p. 2000.

[39] Smith, P. B. and Bond, M. H. Social Psychology across Cultures: Analysis and perspectives. Needham Heights, MA: Allyn \& Bacon, 1994.

[40] Spence-Oatey, H. Cultural Speaking. Managing Rapport Talk through Talk across Cultures. London: Continuum, 2000.

[41] Spencer-Oatey, H. "Managing rapport in talk: Using rapport sensitive incidents to explore the motivational concerns underlying the management of relations," Journal of Pragmatics, 34, pp. 529-545, 2002.

[42] Spiers, J. A. "The use of face work and politeness theory," Quality Health Research, 8, pp. 25-47, 1998.

[43] Suszczynska, M. "Apologizing in English, Polish and Hungarian: Different languages, different strategies," Journal of Pragmatics, 31, pp. 1053-1065.

[44] Takaku, S., Weiner, B., and Ohbuchi, K. "A cross-cultural examination of the effects of apology and perspective taking on forgiveness," Journal of Language and Social Psychology, 20, pp. 144-166, 2001.

[45] $\mathrm{Vu}, \mathrm{T} . \mathrm{T} . \mathrm{H}$. "The role of the concept of face in linguistic behavior research," Vietnamese Journal of Linguistics, 1, pp.8-14, 2002.

[46] Watts, R. J. Politeness. Cambridge: Cambridge University Press, 2003.

[47] Watts, R. J., Ide, S., and Ehlich, K. Politeness in Language: Studies in its History, theory and practice, Eds. Berlin: Mouton de Gruyer.

[48] Weizman, E. "Request hints" in Cross-cultural Pragmatics: Requests and Apologies, J. House and G. Kasper, Eds. Norwood: Ablex Publishing Corporation, 1989, pp. 71-95. 
[49] Wolfson, N. "Compliment in cross-cultural perspective," TESOL Quarterly, 15, pp.117-124, 1981.

[50] Yeung, L. N. T. "Polite requests in English and Chinese business correspondence in Hong Kong," Journal of Pragmatics, 27, pp. 505-522, 1997.
[51] Yli-Jokippi, H. Requests in Professional Discourse: A Cross-cultural Study of British, American and Finnish Business Writing. Helsinki: Suomalailen Tiedeaktemia, 1994. 